\title{
A Retrospective Study on Neonatal Tetanus in Ahmad Sani Yarima Bakura Specialist Hospital Gusau, Zamfara, Nigeria
}

\author{
SHEHU Malam Umar, MUSA Yusuf, \& ADJENE Josiah Obaghwarhievwo* \\ Department of Public and Community Health Sciences, College of Health Sciences, Novena \\ University, Ogume, Delta State, Nigeria.
}

DOI - http://doi.org/10.37502/IJSMR.2021.4507

\begin{abstract}
Neonatal tetanus (NT) is a form of generalized tetanus that occur in a new-born infant (0-28 days) that is not protected by passive immunity due to the fact that the mother is not immune. In this study, a five (5) years retrospective records on neonatal tetanus in Ahmad Sani Yarima Bakura Specialist Hospital, Gusau Zamfara State was investigated. A total of 335 case notes of mothers and their neonates (male and female neonates) who registered at Ahmad Sani Yariman Bakura Specialist Hospital Gusau from January 2016 to December 2020 were obtained, sorted and analysed to obtain socio-demographic records and associated clinical response of neonates who presented with tetanus. The records were extracted and subjected to statistical tests (one way analysis of variance) to compare mean differences across different variables; while pegging p-values $\leq 0.05$ as statistically significant. From the results, a significant number of neonates received antigen and vaccines for BCG and Tetanus at birth. This record however decreased insignificantly for OPVO and HBV1 as compared with the antigen group. Also, the records of clinical signs manifested by neonates on the point of admission showed clinical signs of autonomic instability as compared with others. However, there was a statistically insignificant increase $(\mathrm{p}>0.05)$ in the numbers that came up with fever as against feeding difficulty. Notwithstanding, the records of clinical complications associated with neonates on admission. Here, a mild to moderate signs were noticed for broken bone, pulmonary embolism and pneumonia records as obtained. Also, records on the percentage number of surfaces (based on obtained records) commonly used for child delivery in the study area shows a significant number of delivery cases that repeatedly took place in bed sheets, accounting for a total of 232 (73\%), while plastic $71(22 \%)$ and others $11(4 \%)$ immediately followed respectively. Here, a significant percentage ( 258 of $81 \%$ ) of cord ties depended on clean threads within the study area for the new born, whereas, other sources came next, accounting for about 48 (15\%) of the recorded cases. We observed that neonatal sepsis and transmission usually occurs through infection during unhygienic cutting of the umbilical cord or improper handling of the cord stump. Similar studies that corroborates the reports of this study are highly recommended; especially in other areas with low to intermediate health care and maternal mortality incidences.
\end{abstract}


Keywords: Tetanus, Neonate, Zamfara, Sepsis.

\section{Introduction}

Also known as lockjaw, Tetanus is a serious, but preventable disease that affects body's muscles and nerves. It typically arises from skin wound that become contaminated by a bacterium called Clostridium Tetani which is often found in soil or dust, it is an acute often fatal disease caused by oxytocin produced by Clostridium tetani. Common first signs of tetanus are headache, muscular stiffness of the neck, difficulty in swallowing, rigidity of abdominal muscles, Spasm, sweating and fever [1].

Neonatal tetanus (NT) is a preventable disease with high mortality and accounts for about 5-7\% of neonatal death globally [2]. Mostly in developing countries. Management is mainly focused on relief of symptoms and the prevention of complications such as aspiration pneumonia. A meticulous nursing care is required to prevent occurrence of complications and death caused due to neonatal tetanus [3].

NT is a potentially life threatening disease that is still a health problem in many developing countries. In 2010 and 2013, it was estimated that 58,000 and 49,000 deaths, respectively, occurred from neonatal tetanus (NT) worldwide [4]. The disease is caused by tetanoplasmin, a neurotoxin liberated by anaerobic, spore forming, and gram positive Clostridium tetani. The organism contaminates the umbilical cord or its stump following the use of unhygienic instruments or materials during or after delivery [5]. NT is a preventable disease [6]. Maternal tetanus toxoid immunization is the primary prevention. Neonates receive passive immunity from their vaccinated mothers. In addition, delivery in healthcare centres, avoiding unhygienic childbirth practices and some social taboos and perhaps providing sterile instruments for mothers who elect to have home delivery are important preventive measures [7].

NT is a form of generalized tetanus that occur in a new-born infant ( $0-28$ days) that is not protected by passive immunity due to the fact that the mother is not immune [8]. It usually occurs through infection of the unhealed umbilical stump, particularly when the stump is cut with an unsterile instrument; neonatal tetanus is estimated to kill over 200,000 newborn each year and almost all of the deaths occur in developing countries while very rare in the developed countries [9].

Neonatal tetanus is one of the most reported notifiable diseases, as it tends to occur in areas with poor or no access to health care, it often remain silent within the community [10]. It is estimated that maternal tetanus is possible for $5 \%$ of maternal mortalities, particularly in the developing World [11]. Cases of neonatal tetanus have been reported in the area of study, but many of the non-reported cases and deaths occur at home before the baby reaches two weeks of age.

According to the World Health Organization (WHO)'s global immunization news of March, 2013, Nigeria is one of 30 remaining high-risk countries that have not achieved the 
Maternal and Neonatal Tetanus Elimination (MNTE) goal yet. Available data indicates that 18 states (out of 37) are at risk for maternal and neonatal tetanus [12].

Many hospital based studies have identified neonatal tetanus as a problem of high magnitude in Nigeria. Maternal immunization and improved obstetric and neonatal care are the main strategies in Nigeria for improving protection against neonatal tetanus [11]. Recently, the high-risk approach of conducting tetanus toxoid (TT) Supplementary Immunization Activities (SIAs) targeting women of reproductive age was conducted in three states of the federation and selected Local Government Areas (LGAs) in 5 other states including Borno. Health education to modify harmful cultural practices that directly encourage the risk of acquisition of tetanus is also useful.9,10 Nigeria plans to achieve elimination in a phased manner by focusing on two zones (South-east and South-west) in 2013-2014 followed by the remaining four zones. The bulk of African Countries, Nigeria inclusive, have a very young population with more women in reproductive age group [12]. This further underscores the need for increase action towards maternal tetanus immunization of women of child-bearing age if the scourge is to be controlled.

\section{Materials and Methods}

\section{Study Location}

This study is conducted in Gusau Town in Zamfara State. Gusau emerged as a Local Government in 1989, and has 3,3064 square kilometers with the population of about 383,162 according to 2006 census figures. The Town is by Central of Zamfara along Sokoto Road and is bordered with Sokoto State at the West, Niger Republic at the North, kebbi state at the South and Katsina State at the East. Gusau Local Government has one general Hospital and 89 health facilities including 13 primary health care centers within the Local Government Area. The major languages spoken include; Hausa and Fulani.

\section{Scope of Study}

The scope of this study was to assess the burden of neonatal tetanus in Ahmad Sani Yariman Bakura Specialist Hospital, Gusau, Zamfara State from January 2016 to December, 2020

\section{Study Population}

The study population consists of records of number of neonatal tetanus patients recorded at Ahmad Sani Yariman Bakura Specialist Hospital Gusau from January 2016 to December 2020. Pregnant women or mothers that attended antenatal care (ANC) in the hospital at the same period as well as the women of child bearing age that received tetanus toxoid immunization was included in the study.

\section{Sampling Techniques and Sample Size Determination}

The required sample size was determine using simple population proportion formula considering;

Proportion $\mathrm{P}=$ value 50\%, confidence level $95 \%$ and within 5\% precision. 
The minimum sample size was 335 .

\section{Inclusion Criteria}

The study includes case notes of mothers and their neonates (male and female neonates) who registered at Ahmad Sani Yariman Bakura Specialist Hospital Gusau from January 2016 to December 2020 respectively.

\section{Exclusion Criteria}

This study excludes neonates who was registered in other health facilities in Gusau Local Government, Zamfara State. Another exclusion is any patient case notes before January 2016 to December, 2020 was excluded from the study.

\section{Method and Instrument of Data Collection}

Quantitative method of data collection was employed in this study. The instruments used will the data extraction instrument which was designed from research questions. Informed consent was obtained from the Hospital administration before the study commences. Relevant information was extracted including age of the newborn, whether in-born or out-born; booking status, place of antenatal supervision of un-booked mothers, period of onset of the infection, portal of entry and mothers immunization status etc. the duration and outcome of treatment was also derived.

\section{Method of Data Analysis}

The quality of data collected was checked thoroughly in the field. This entails review of the patterns of records of each case note as recorded in the data abstraction instrument. Necessary adjustment was made on the field and serial numbers assigned for easy identification and recall of record with problem. Code was assigned after developing a coding guide where it was further entered in to the computer for analysis. Data was analysed using descriptive statistics; Mean, Standard deviation and percentage distribution (data were presented using frequency table and chart) while inferential statistic was used where appropriate.

\section{Validity and Reliability of Instrument}

Validity of the instrument was ensured by given the instrument to experts such as medical personnel researchers and public health professionals to examine the items and make necessary contributions to the data abstraction instrument that was used to construct validity.

\section{Instrument for Data Collection}

Data was collected from the available records from out-patient Department, maternity unit, and pediatric unit at Ahmad Sani Yariman Bakura Specialist Hospital, Gusau, from January 2016 to December 2020. Expanded program on Immunization Unit at health Department in the Local Government secretariat records was reviewed.

\section{Limitation of Study}


Lack of having access to reach household wives: due to religious and traditional believes, not all men allow the researcher to have an interaction session or focus group discussion with their wives.

\section{Ethical Consideration}

An introductory letter was obtained from the Department of Public and Community Health ( $\mathrm{PCH}$ ), Novena University for the Medical Director (MD) of the Hospital who gave the approval to go ahead. The study followed the ethical principles guiding the use of human participants in research which are: respect for persons, beneficence, and justice. Hence the following activities was performed on the ethical grounds; adequate information on the purpose of the study was given to the hospital administration, and informed consent sought from the Hospital management. Furthermore, the data collected was used for research purpose only, and confidentiality ensured.

\section{Results}

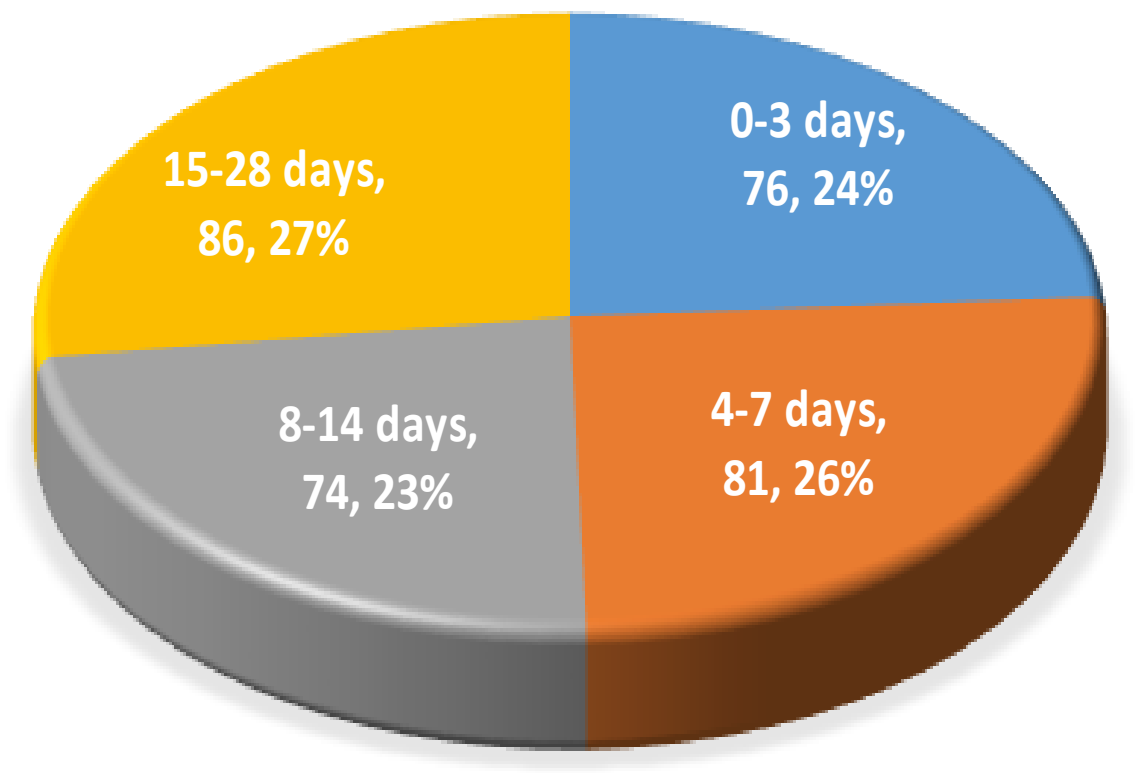

Figure I: Summary of Socio-demographic Characteristics of Respondents by Age

From figure I (above), of the total 335 neonates were accessed, about 87 of them (27\%) were between 15 and 28 days old, whereas 74 of them (23\%) where in their 8-14 th day post birth, and 81 (26\%), 76 (24\%) of the other assessed neonates were of the age brackets 4-7 days and 0-3 days respectively. 


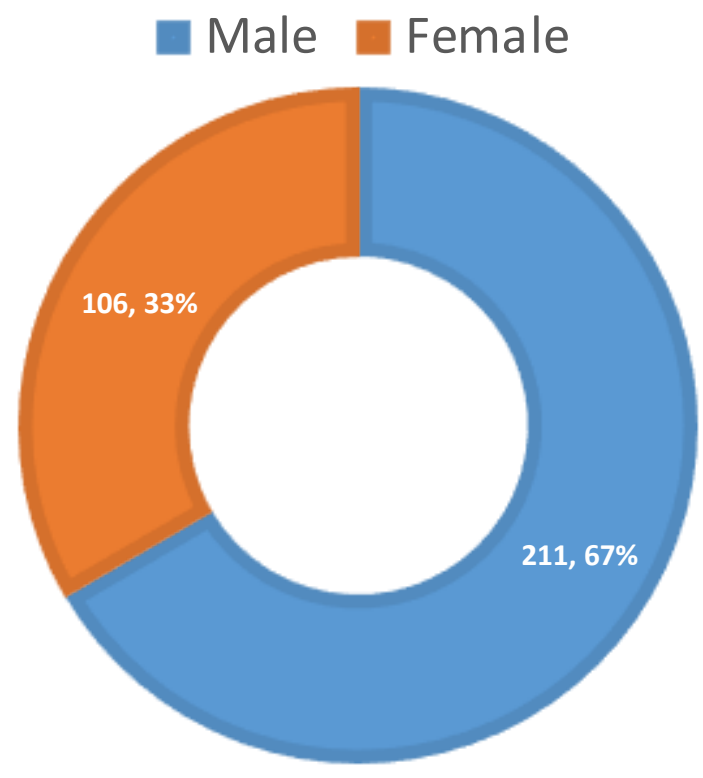

Figure II: Summary of Total Number of Sampled Neonates by Gender

Figure II (above) gives a summary of the number of cases considered in the course of data collection. From the figure, about 211 (67\%) of the neonates were of the male gender, with $106(33 \%)$ of them belonging to the female gender.

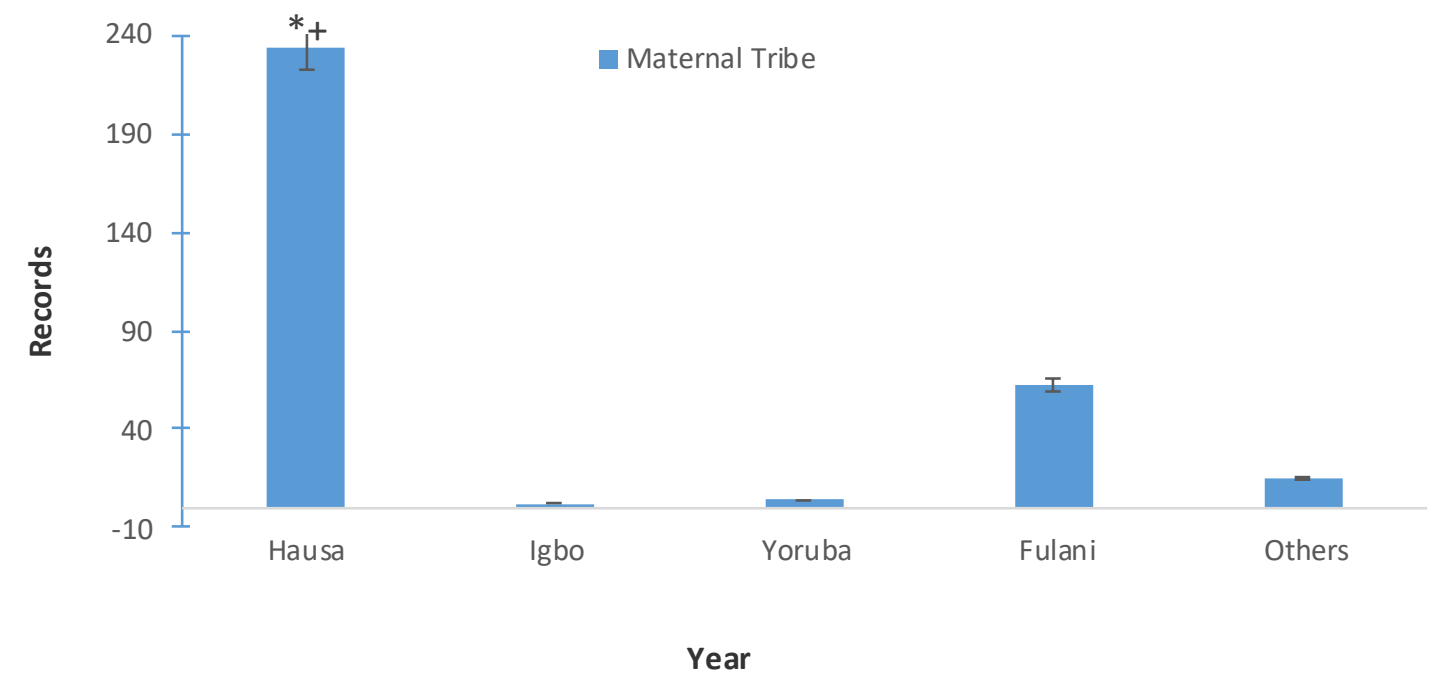

Figure III: Socio-Demographic Characteristics of Neonates by Maternal Tribe

From figure III (above), the socio-demographic properties of sampled neonates by maternal tribe is shown to be significantly $(p<0.05)$ higher in Hausa as compared to others. Igbos and 
130 | International Journal of Scientific and Management Research 4(5) 124-140

Yoruba neonates came least in the chat with $2 \%$ and $4 \%$ cases relative to Hausas of the total 317 samples obtained.

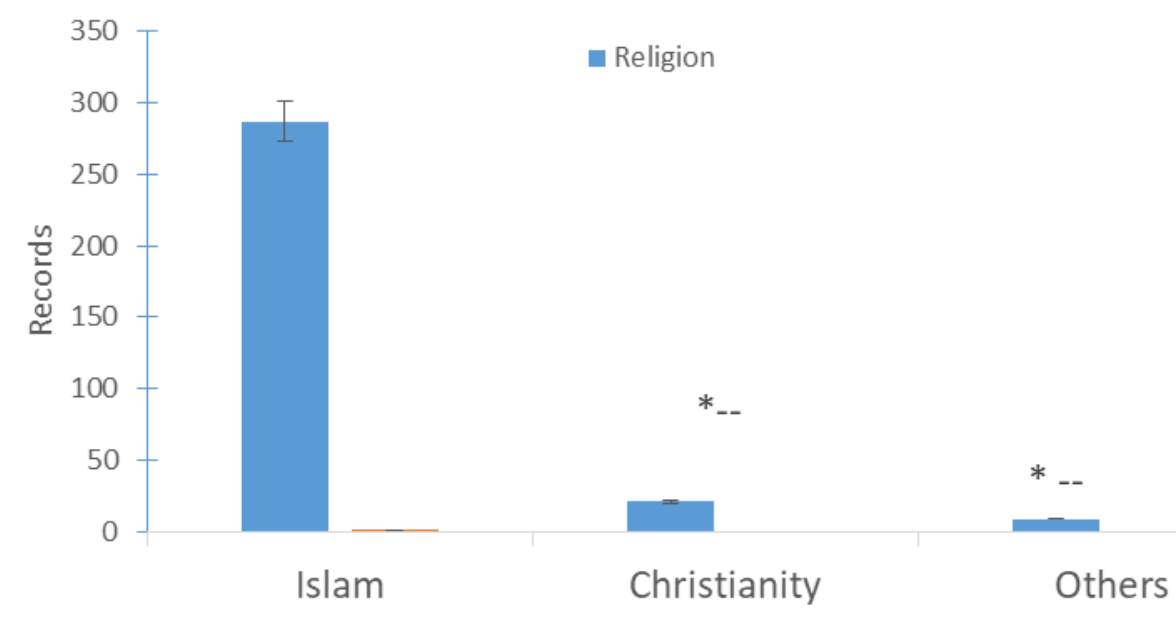

Figure IV: Socio-Demographic Characteristics of Neonates by Religion

Above figure IV shows the socio-demographic properties of accessed neonatal cases by religion. From the chat, a statistically significant decrease $(p>0.05)$ is seen in Christian neonate titanus cases as compared with those in islam. The same goes for non-Christian neonates as against those of islam $*_{--}=$significant decrease

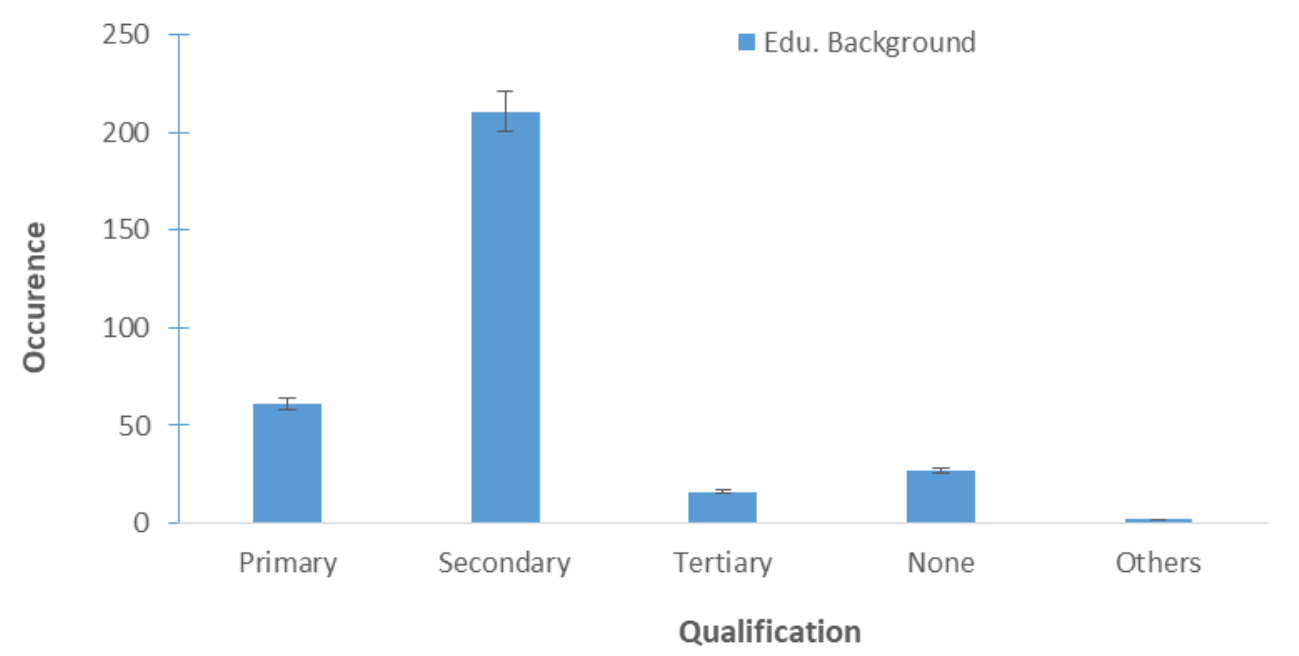

Figure V: Comparative Effects of Maternal Educational Status on Incidences of Occurrence of Neonatal Tetanus

The figure above $(V)$ compares the educational background of mothers with the incidences of occurrence of neonatal tetanus. Here, there is an inconsistent attenuation for the various 
131 | International Journal of Scientific and Management Research 4(5) 124-140

academic backgrounds compared with those who had primary education only. However, mothers with secondary educational background tent to have more neonatal tetanus cases as compared with others.

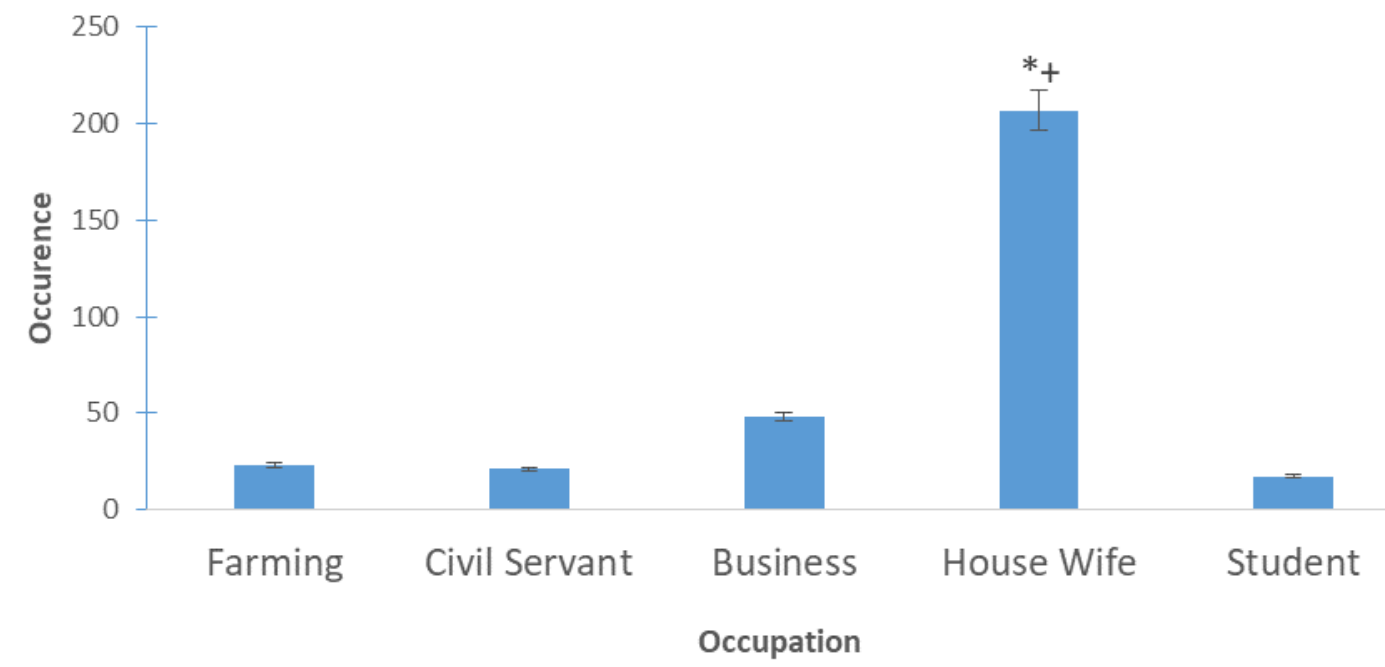

Figure VI: Comparative Effects of Maternal Occupation on Incidences of Occurrence of Neonatal Tetanus

*+: Significant increase

The figure above (VI) is a comparative summary of maternal occupational records on neonatal tetanus in the study area. From the chat, a significant increase in neonatal tetanus is seen in full time house wives that actively occupied women

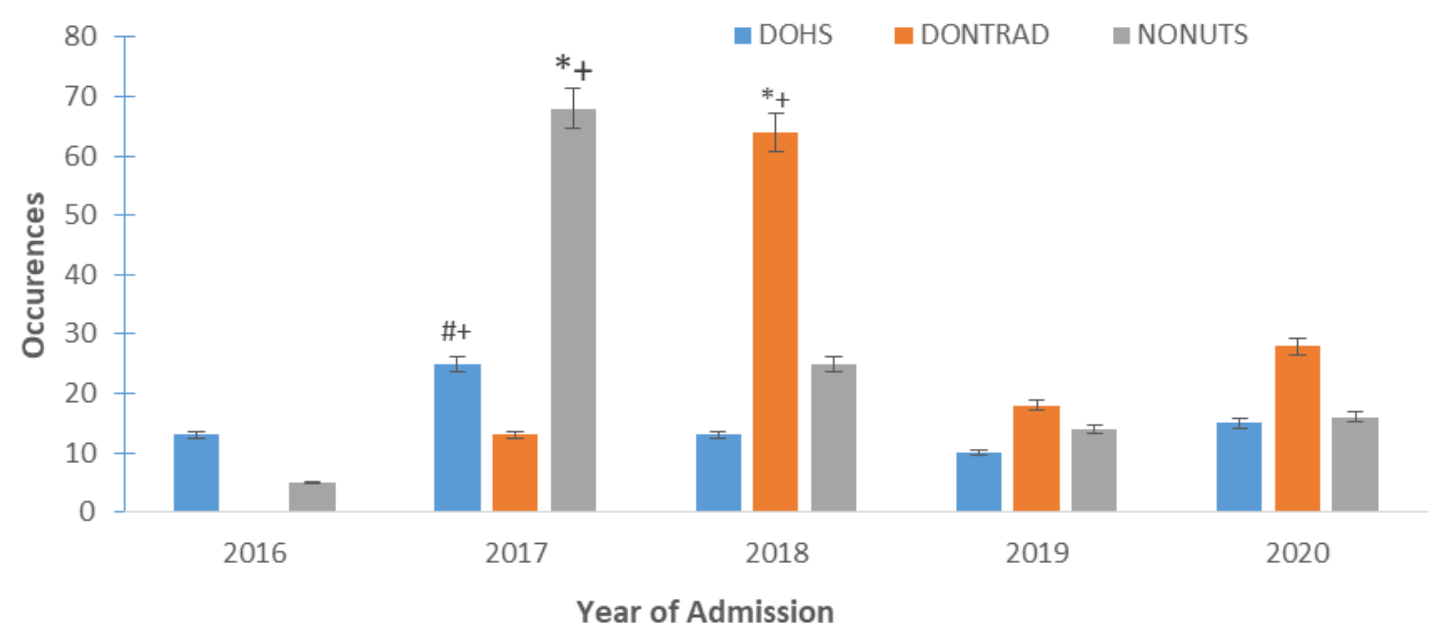

Figure VII: Active Cases of Neonatal Tetanus 
Key: DOHS = Duration of Hospital Stay by mothers, DONTRAD = Days of Neonatal Tetanus Re-emergence After Discharge, NONUTS $=$ Number of tetanic Neonates Unable to Suckle

The figure above (VII) is a comparative summary of the number of active cases assessed for maternal-neonate tetany within the study area. From the chat, NONUTS and DOHS showed a statistically significant increase $(p<0.05)$ in 2017 and 2018 respectively as compared with other assessed years. Whereas, DONTRAD returned an insignificant increase for year 2017 as against others.

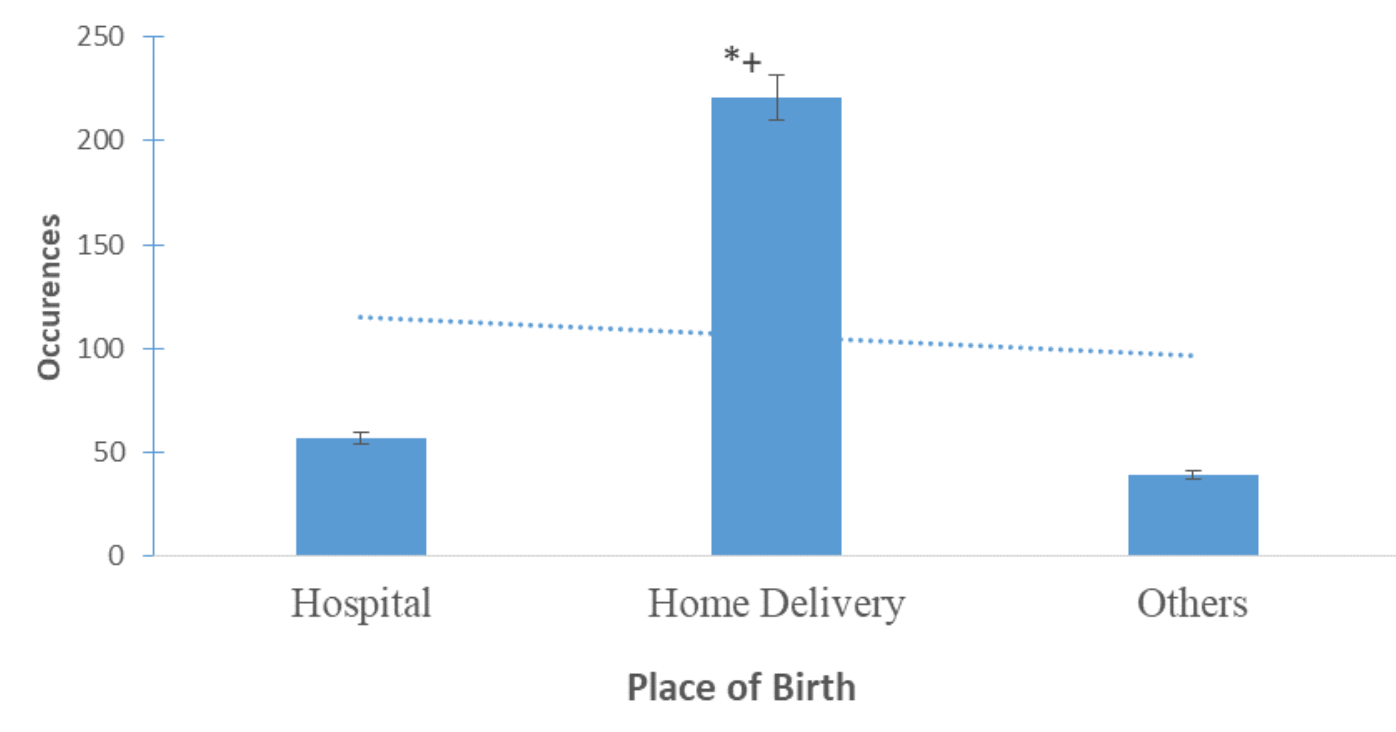

Figure VIII: Active Cases of Neonatal Tetanus Based on Place of Birth

*+: Significant increase

The figure above (VIII) is a comparative summary of neonatal tetanus status based on place of birth. Here, three records were assessed; hospital, home and others. From the chat, neonates delivered at home showed a statistically significant $(p<0.05)$ increase in Tetany than those delivered in the hospital and other areas. 


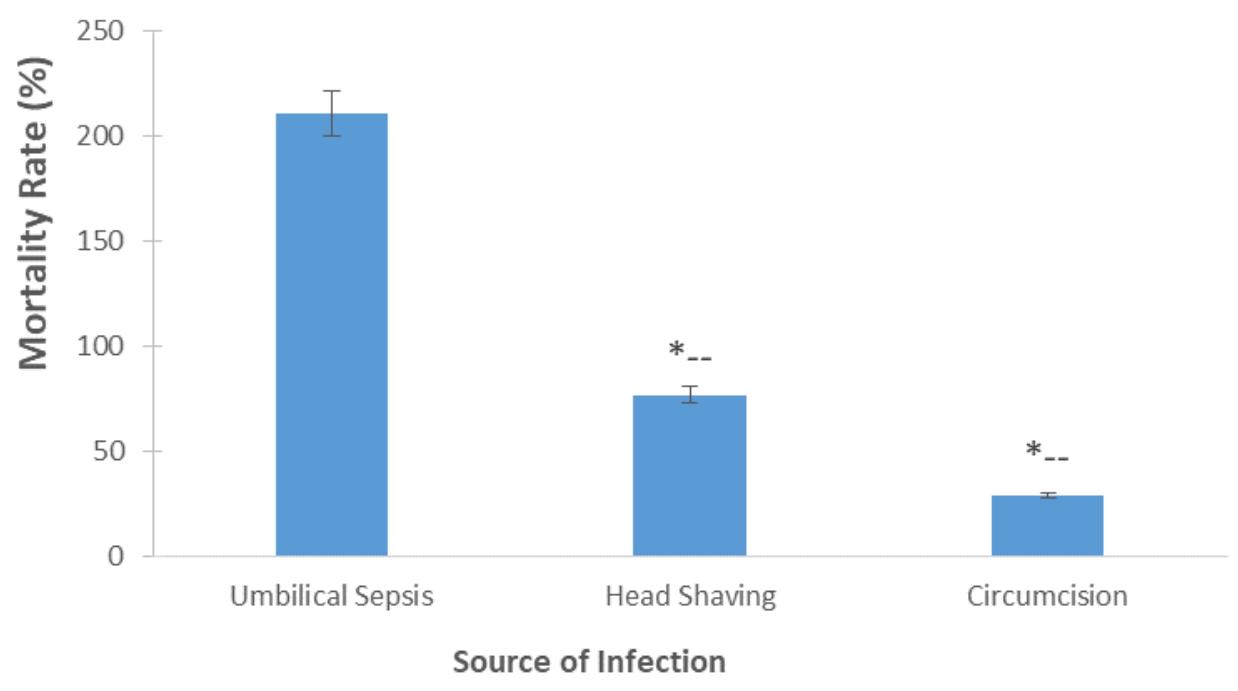

*--: Significant decrease

Figure IX: Source of Infection as a Factor for Neonatal Tetanus

From the figure above (IX) head shaving and circumcision as a source of neonatal tetanus showed a statistically significant decrease $(p<0.05)$ compared with umbilical sepsis in the new born. This implies that umbilicus is the most probable route of tetanus infection in the neonates within the study area.

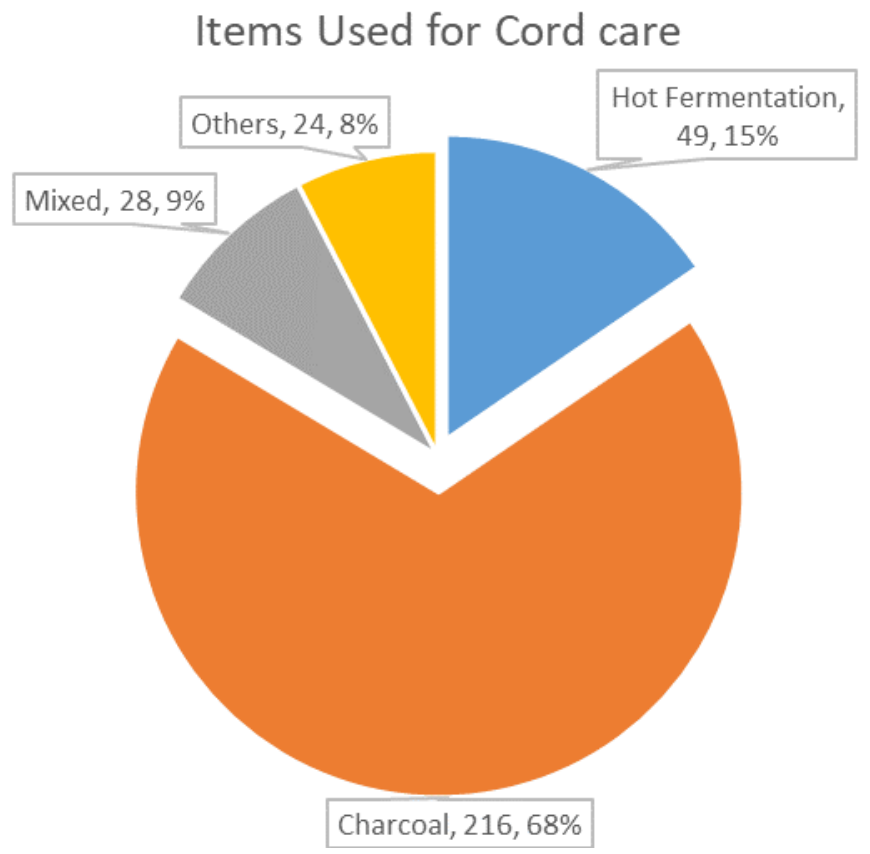

Figure X: Common Items Used for Cord Cares

Figure X above shows the percentage number of items used for cord care in the study area. From the figure, a significant number of record shows charcoal as the most commonly used 
134 | International Journal of Scientific and Management Research 4(5) 124-140

item, accounting for $216(68 \%)$ of the total records, with Hot Fermentation following next at about $15 \%$ (40) rate.

Delivery Surface

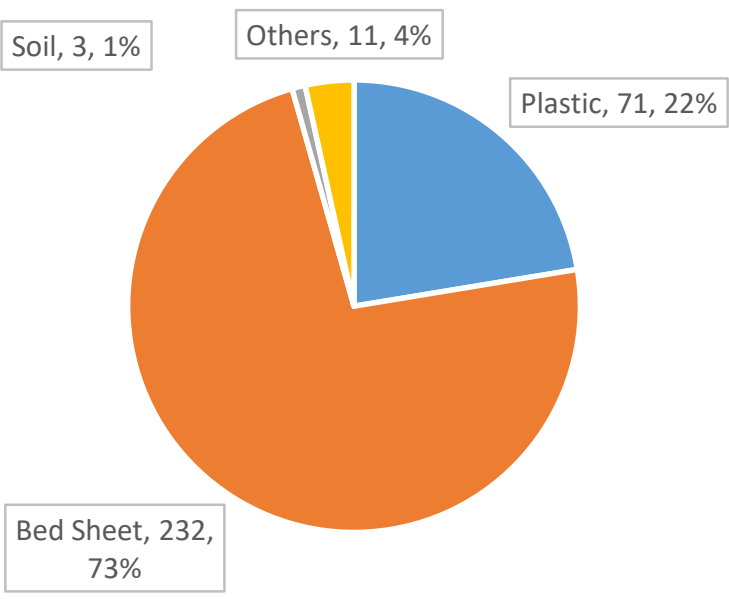

Figure XI: Common Surfaces Used for Child Delivery

Figure XI above shows the percentage number of surfaces (based on obtained records) commonly used for child delivery in the study area. From the chat, a huge number of delivery cases reportedly took place in the bed sheet, accounting for a total of 232 (73\%), while plastic $71(22 \%)$ and others 11 (4\%) immediately followed respectively.

\section{Cord tie Hygiene}

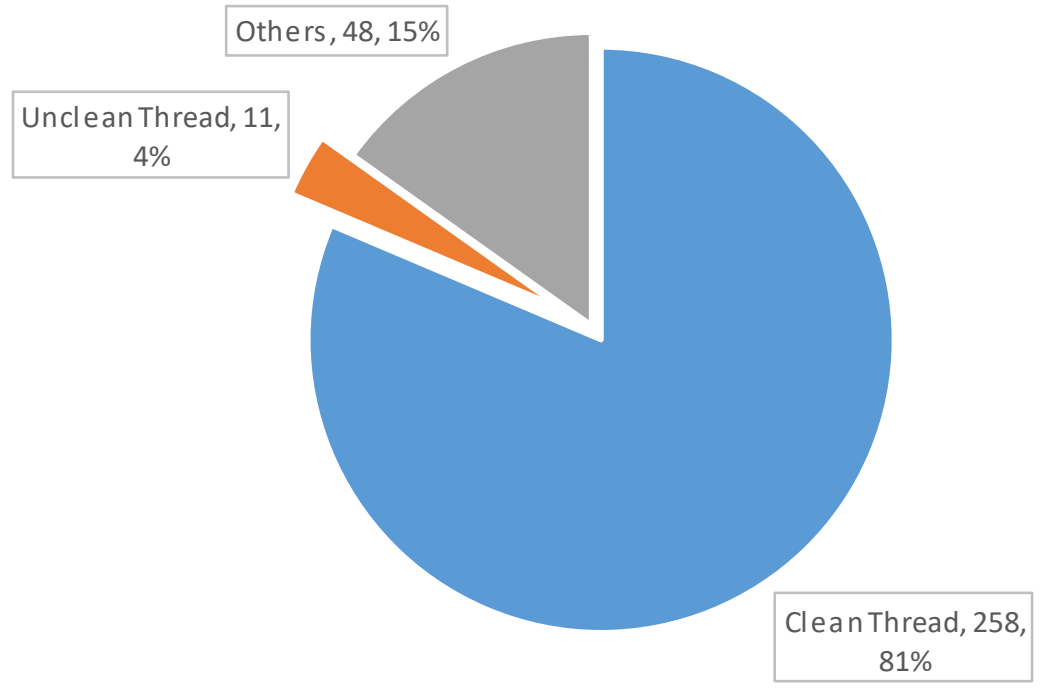

Figure XII: Hygienity of Cord Tie 
135 | International Journal of Scientific and Management Research 4(5) 124-140

From the figure above, a huge percentage (258 of 81\%) of cord ties relied on clean threads within the study area for the new born, whereas, other sources came next, accounting for about 48 (15\%) of the recorded cases.

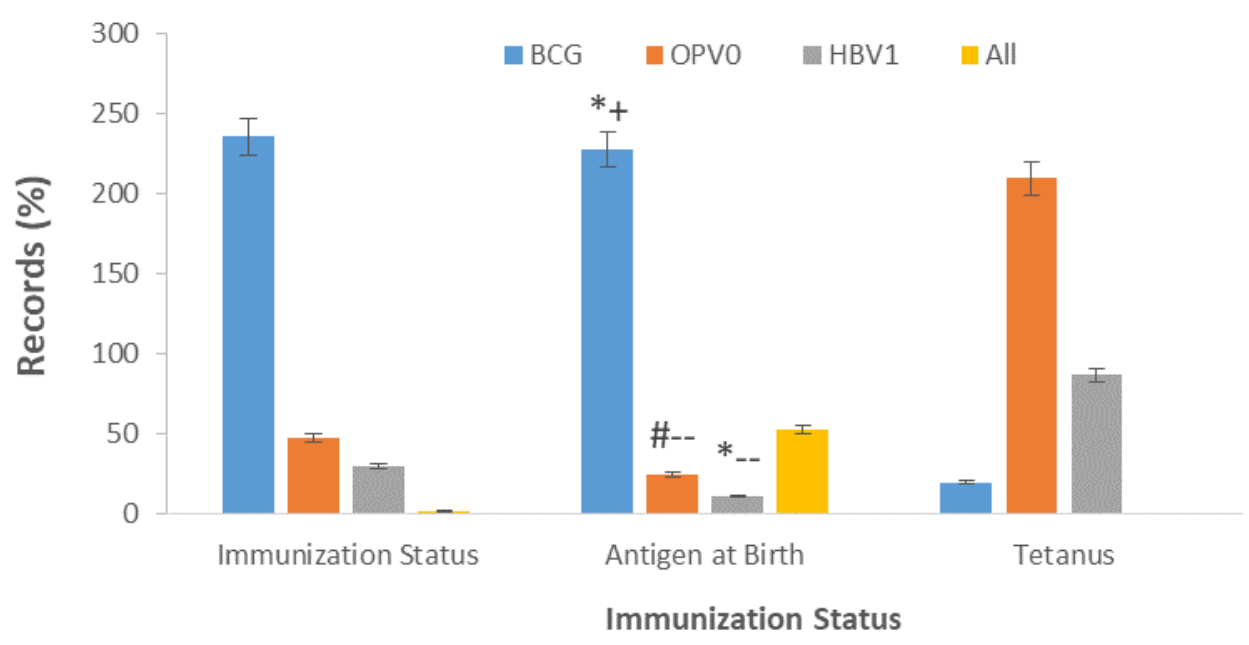

*+: Significant increase, \#-- Insignificant decrease, *-- = Significant decrease

Figure XIII: Neonatal Immunization Status

Figure XIII above shows the immunization status of neonates at birth within the study area. From the records obtained, a significant number of neonates received antigen and vaccines for BCG and Tetanus at birth. This record however decreased insignificantly for OPVO and HBVI as compared with antigen.

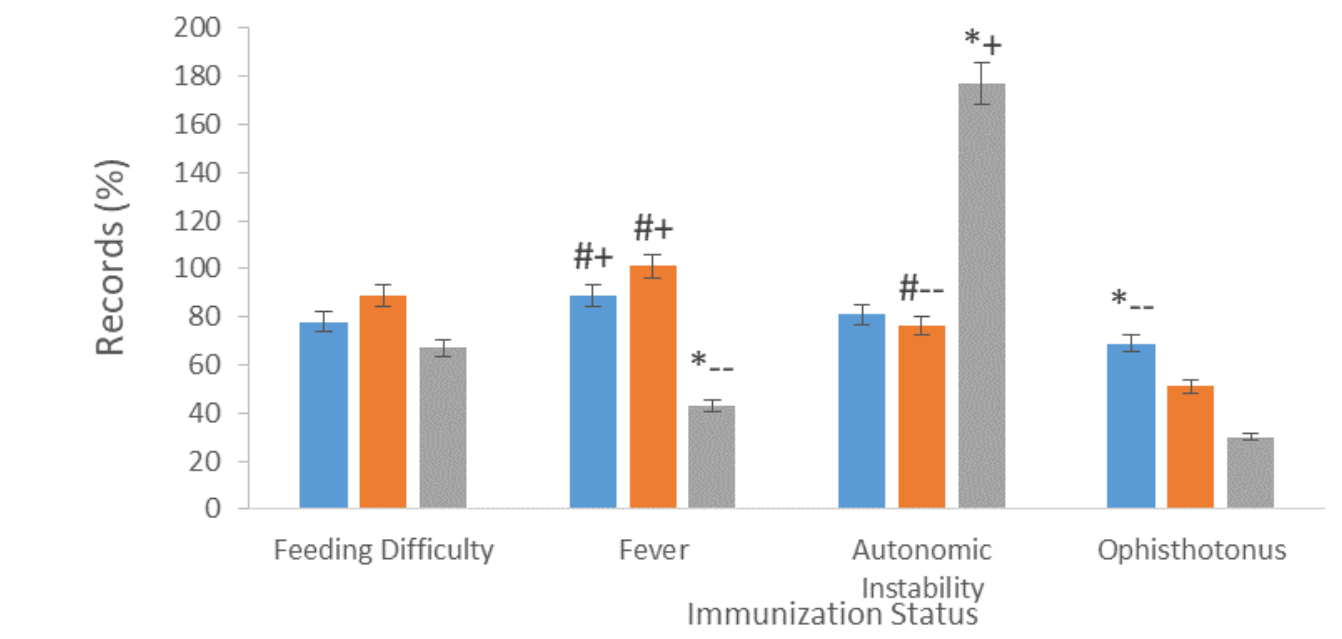

$*_{--}=$statistically significant decrease $(p<0.05)$, \#-- = insignificant decrease, \#+ = insignificant increase 


\section{Figure XIV: Neonatal Clinical Features on Admission}

Figure XIV above shows the records of clinical signs manifested by neonates on the point of admission. From the chat, a significant number of the neonates showed clinical signs of autonomic instability as compared with others. However, there was a statistically insignificant increase $(p>0.05)$ in the numbers that came up with fever as against feeding difficulty

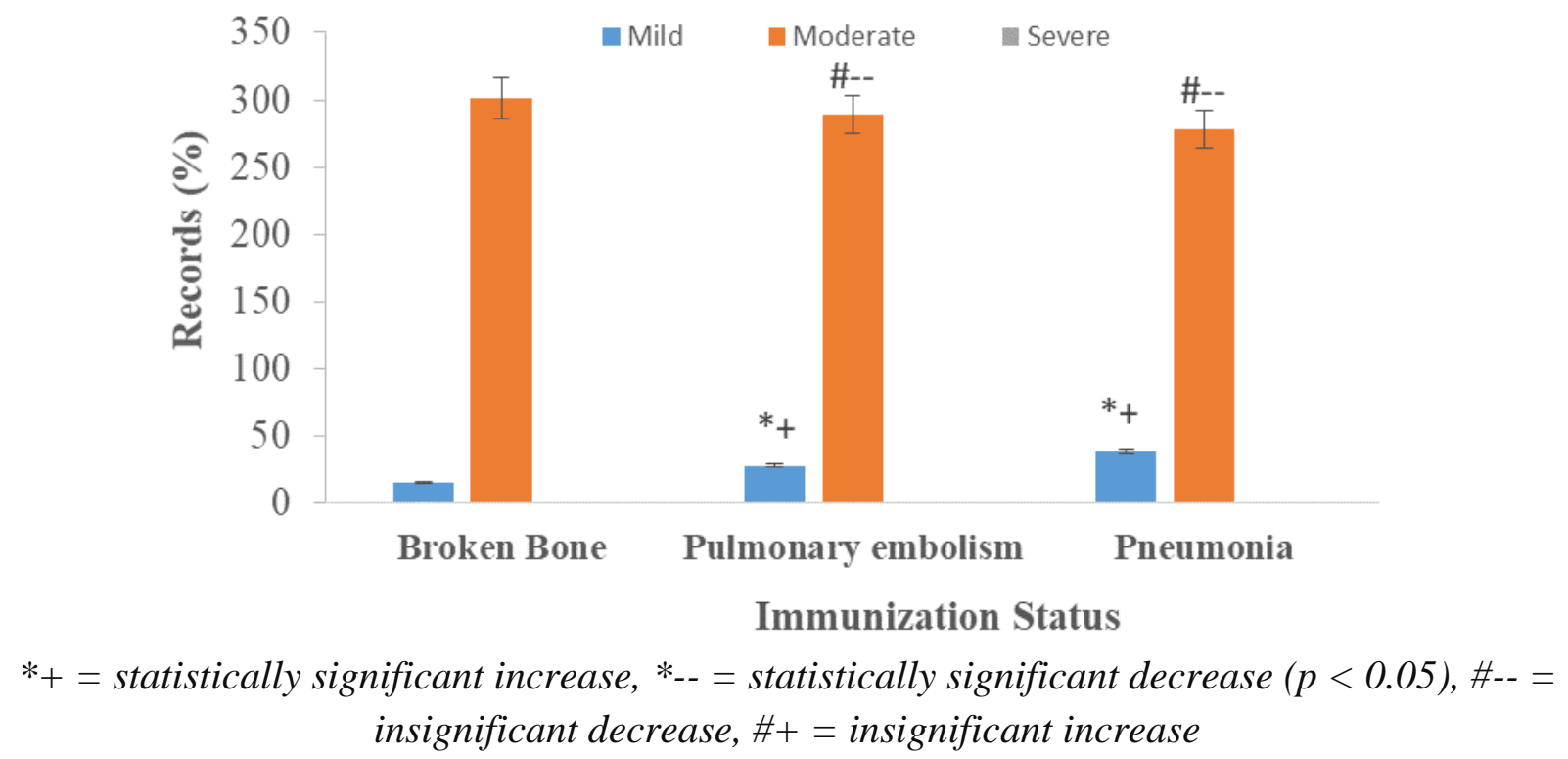

Figure XV: Neonatal Complications and Outcomes

Figure XV above shows the records of clinical complications associated with neonates on admission. Here, a mild to moderate signs were noticed for broken bone, pulmonary embolism and pneumonia records as obtained. This though proved insignificant across board. However, pneumonias and pulmonary edema returned a statistically significant increase as compared with broken bone neonates.

\section{Discussion}

Neonatal tetanus (NT) is a preventable disease with high mortality and accounts for about $5-7 \%$ of neonatal death globally [2]. Mostly in developing countries. Management is mainly focused on relief of symptoms and the prevention of complications such as aspiration pneumonia. A meticulous nursing care is required to prevent occurrence of complications and death caused due to neonatal tetanus [3]. NT is a potentially life threatening disease that is still a health problem in many developing countries. In 2010 and 2013, it was estimated that 58,000 and 49,000 deaths, respectively, occurred from neonatal tetanus (NT) worldwide [4]. The disease is caused by tetanoplasmin, a neurotoxin liberated by anaerobic, spore forming gram positive 
Clostridium tetani. In this study, a five (5) years retrospective records on the neonatal tetanus in Ahmad Sani Yarima Bakura Specialist Hospital, Gusau Zamfara State was evaluated. A total of 335 case notes of mothers and their neonates (male and female neonates) who registered at Ahmad Sani Yariman Bakura Specialist Hospital Gusau from January 2016 to December 2020 were obtained, sorted and analysed to obtain socio-demographic records and associated clinical response of neonates who presented with tetanus were extracted and subjected to statistical analysis to compare mean differences across different variables.

\section{Summary of Demographic Data}

In this study, the socio-demographic records of mothers and assessed neonates are summarized in figure I - V. From the chats, a total 335 files were accessed from the hospital for the admission years of January 2016 to December 2020. From the records. From figure I, of the total 335 accessed neonatal records, about 87 of them (27\%) fell between 15 and 28 days old, while 74 of them (23\%) where in their 8-14 $4^{\text {th }}$ day post birth, and $81(26 \%), 76(24 \%)$ of the other assessed neonates were of the age brackets 4-7 days and 0-3 days respectively.

Again, figure II summarizes the number of considered cases at the point of data collection. From the figure, not less than 211 (67\%) of assessed neonates records were of the male gender, while 106 (33\%) were females. Figure III also presents the socio-demographic attributes of sampled neonates by maternal tribe. Here, there was a significant $(\mathrm{p}<0.05)$ higher number of Hausas as compared to others. Igbos and Yoruba neonates came least in the chat with $2 \%$ and $4 \%$ cases relative to Hausas of the total 335 samples obtained. Also, figure IV has the socio-demographic characteristics of accessed neonatal cases by religion. From the chat, a statistically significant decrease $(\mathrm{p}<0.05)$ is observed in Christian neonates that presented with tetanus as compared with Islam. The same goes for non-Christian neonates as against those of islam. Comparisons of maternal educational status with incidences of occurrence of neonatal tetanus showed an uneven reduction for the various academic backgrounds compared with those who had primary education only. However, mothers with secondary educational background tent to have more neonatal tetanus cases as compared with others.

\section{Comparative Effects of Maternal Occupation and Routes of Infection on Incidences of Occurrence of Neonatal Tetanus}

From figure VI of current study, a comparative summary of maternal occupational records on neonatal tetanus in the study area was assessed and presented. From the chat, a statistically significant increase $(\mathrm{p}<0.05)$ was observed in neonates who presented with tetanus, especially for full time house wives that those (mothers) who were actively engaged in one occupation or the other. Till date, neonatal tetanus has been reported to be one of the leading causes of newborn deaths in some parts of the developing world. Recent observation has shown that the risk of developing tetanus in new born may be directly related to occupational status of the mothers. This report concurs with the earlier reports of Erege, (2006) [8]. 
Also, a clear look at figure VII comparatively summarizes the number of active cases assessed for maternal-neonate tetanus for the study area. Here, the number of neonates who presented with tetanus while unable to suckle and duration of hospital stay by mothers showed a statistically significant increase ( $\mathrm{p}$ < 0.05) in 2017 and 2018 respectively as compared to other assessed years from the record. However, the days of neonatal tetanus re-emergence following the discharge of their mothers showed a statistically insignificant increase $(p>0.05)$ for year 2017 as against others. By implication, the VIII, 4.8 also comparative summarized the tetanus status of assessed neonate's records based on place of birth. From the figure, three records were assessed; hospital, home and others. Here, neonates delivered at home apparently showed a statistically significant $(\mathrm{p}<0.05)$ increase in their presentation with tetanus than those delivered in the hospital or other areas. It is also noteworthy that head shaving and circumcision as a source of neonatal tetanus showed a statistically significant decrease $(\mathrm{p}<0.05)$ compared with umbilical sepsis in the new born (figure IX). The implication of this is that umbilicus is the most possible route of tetanus infection in the neonates within the study area. Previous reviews of neonatal tetanus at the University of Maiduguri Teaching Hospital, North-eastern Nigeria, shows that neonatal tetanus is a vaccine preventable disease and is a leading cause of neonatal mortality in developing countries. The effectiveness of hygienic umbilical cord care, especially relative to the route of neonatal septisemia in the prevention of the disease was established by Alhaji et al., (2019) [13]. Their observations agrees strongly with those of current study.

\section{Comparative Effects of Umbilical Cord Cares and Surfaces Used on Child Delivery and Neonatal Septisemia}

Figure $\mathrm{X}$ of current study reveals that the percentage number of items used for cord care had a significant number of record that shows charcoal as the most commonly used item, accounting for $216(68 \%)$ of the total records, with hot fermentation following next at about $15 \%$ (40) rate. Also, records on the percentage number of surfaces (based on obtained records) commonly used for child delivery in the study area shows a huge number of delivery cases that repeatedly took place in the bed sheet, accounting for a total of $232(73 \%)$, while plastic $71(22 \%)$ and others 11 (4\%) immediately followed respectively (figure XI). From the figure, a significant percentage ( 258 of $81 \%$ ) of cord ties depended on clean threads within the study area for the new born, whereas, other sources came next, accounting for about $48(15 \%)$ of the recorded cases. Several reports have suggested that transmission usually occurs through infection during unhygienic cutting of the umbilical cord or improper handling of the cord stump, particularly when the cord is "treated" or "dressed" with materials that may be contaminated with tetanus spores, for example, with animal dung [14]. The report from current study also agrees with those of Wilfret and Hotez, (2015).

\section{Comparative Effects of Neonatal Immunization Status and Clinical Features on Admission on Tetany}


Figure XIII shows the immunization status of neonates at birth within the study area. From the records obtained, a significant number of neonates received antigen and vaccines for BCG and Tetanus at birth. This record however decreased insignificantly for OPV0 and HBV1 as compared with antigen. Also, the records of clinical signs manifested by neonates on the point of admission showed clinical signs of autonomic instability as compared with others. However, there was a statistically insignificant increase $(p>0.05)$ in the numbers that came up with fever as against feeding difficulty. Notwithstanding, the records of clinical complications associated with neonates on admission. Here, a mild to moderate signs were noticed for broken bone, pulmonary embolism and pneumonia records as obtained. This though proved insignificant across board. However, pneumonias and pulmonary edema returned a statistically significant increase as compared with broken bone neonates.

While no other disease clinically resembles full-blown neonatal tetanus, there are a number of medical conditions that reportedly display one or more similar clinical characteristics. The differential diagnosis should take into account causes of neonatal convulsions. In general, there are three etiologic categories of neonatal convulsions

\section{Conclusion}

Neonatal Infection is acquired by contamination of wound with tetanus spores. The range of injuries and accidents which may lead to tetanus. In this study, we investigated a five (5) years retrospective records on the neonatal tetanus in Ahmad Sani Yarima Bakura Specialist Hospital, Gusau Zamfara State. We observed that neonatal sepsis and transmission usually occurs through infection during unhygienic cutting of the umbilical cord or improper handling of the cord stump. Current study also observed a significant $(\mathrm{p}<0.05)$ higher number of Hausa neonates came up septisemic as compared to others. Igbos and Yoruba neonates came least in the chat with $2 \%$ and $4 \%$ cases relative to Hausas of the total 335 samples obtained

\section{References}

1) United Nation International Children Emergency Fund (UNICEF), (2018). Maternal and Neonatal Tetanus Elimination by 2005; strategies for maintaining elimination. Retrieved from www.unicef/womenstatistics/org.

2) Brye J, Boschi-Pinto C, Shibuya K, Black RE. World Health Organization (WHO) estimates of the causes of death in children. Lancet. 2005; 365:1147-52.

3) Lawn JE, Cousens S, Darmstadt GL, Paul V, Martines J. (2004). Why are 4 million newborn babies dying every year? Lancet. ; 364:2020.

4) Black RE, Cousens S, Johnson HJ, Lawn JE, Ruda I, Bassani D, (2010). Global, regional and national causes of mortality in 2008: a systematic analysis.p.1e19.http://www.who.int/immunizationymrtalityydiseasesylancet_2010_with. Appendix.pdf. 
5) Khan R, Vandelaer J, Yakubu A, Raza AA, Zulu F. (2015) Maternal and neonatal tetanus elimination: from protecting women and newborns to protecting all. Int $\mathrm{J}$ Womens Health; 7:171-180.

6) Thwaites CL, Beeching NJ, Newton CR. Maternal and neonataltetanus. Lancet 2015; 385:362e70.

7) Demicheli V, Barale A, Rivetti A. (2013). Vaccines for women to prevent neonatal tetanus.

8) Erege, C.O. (2006). Ovulectomy as an epidemiology factor in Neonatal Tetanus Mortality: observation from a cluster survey. West African Journal medicine 4 (7) 356358.

9) United Nation International Children Emergency Fund (UNICEF), (2018). Maternal and Neonatal Tetanus Elimination by 2005; strategies for maintaining elimination. Retrieved from www.unicef/womenstatistics/org.

10) World Health Organization, (WHO). (2009). Maternal and Neonatal Tetanus Elimination Geneva.

11) Adovohekpe P, Onimisi A, Ekpemauzor C. WHO. Global Immunization News March; 2013. Planning meeting on maternal and neonatal tetanus elimination in Nigeria.

12) Cincotta R. (2012). The future of sub-Saharan Africa's tentative fertility decline.[LastaccessedonAvailablefrom:http://www.newsecuritybeatorg/2010/08/futureof-sub-sharan-africas-tentative_25.html.

13) Alhaji, M. A., Bello, M. A., Elechi, H. A., Akuhwa, R. T., Bukar, F. L., \& Ibrahim, H. A. (2019). A review of neonatal tetanus in University of Maiduguri Teaching Hospital, northeastern Nigeria. Niger Med J, 54(6): 398-401.

14) Wilfret C, Hotez PJ. (2015). Tetanus (lockjaw) and neonatal tetanus. In: Gershon A, Hotez PJ, Katz S. Krugman's infectious diseases of children, 11th ed. St. Louis: C.V. Mosby Company: 655-662.

\section{Works Cited}

SHEHU Malam Umar, MUSA Yusuf, \& ADJENE Josiah Obaghwarhievwo2021A Retrospective Study on Neonatal Tetanus in Ahmad Sani Yarima Bakura Specialist Hospital Gusau, Zamfara, Nigerialnternational Journal of Scientific and Management Research0405124140doihttp://doi.org/10.37502/IJSMR.2021.4507 